Terr. Atmos. Ocean. Sci., Vol. 18, No. 2, 359-377, June 2007

\title{
Mesoscopic Structural Observations of Cores from the Chelungpu Fault System, Taiwan Chelungpu-Fault Drilling Project Hole-A, Taiwan
}

\author{
Hiroki Sone ${ }^{1,6, *}$, En-Chao Yeh ${ }^{2,5}$, Taichi Nakaya ${ }^{3}$, Ji-Hao Hung ${ }^{4}$, Kuo-Fong Ma ${ }^{4}$, \\ Chien-Ying Wang ${ }^{4}$, Sheng-Rong Song ${ }^{5}$, and Toshihiko Shimamoto ${ }^{1}$
}

(Manuscript received 25 July 2005, in final form 23 January 2007)

\begin{abstract}
Structural characteristics of fault rocks distributed within major fault zones provide basic information in understanding the physical aspects of faulting. Mesoscopic structural observations of the drilled cores from Taiwan Chelungpu-fault Drilling Project Hole-A are reported in this article to describe and reveal the distribution of fault rocks within the Chelungpu Fault System.

The Chelungpu Fault System in Hole-A was encountered at a depth of between $1050-1250 \mathrm{~m}$ where deformation structures increased. Three major fault zone structures were found at approximate depths of 1111, 1153, and $1221 \mathrm{~m}$. The presence of wide fault rock regions were mostly concentrated in these 3 fault zones. The fault zone at $1111 \mathrm{~m}$ mainly consists of a nearly brecciated fracture zone and a clayey fault gouge zone of about $1.05 \mathrm{~m}$ in thickness. Fault rocks from the fault zone at $1153 \mathrm{~m}$ are characterized by the presence of sand grains in the matrix content, consisting of
\end{abstract}

${ }^{1}$ Department of Geology and Mineralogy, Kyoto University, Kyoto, Japan

${ }^{2}$ Kochi Institute for Core Sample Research, Japan Agency for Marine-Earth Science and Technology, Kochi, Japan

${ }^{3}$ Department of Natural Environmental Science, Kochi University, Kochi, Japan

${ }^{4}$ Department of Earth Sciences and Institute of Geophysics, National Central University, Chung-Li, Taiwan, ROC

${ }^{5}$ Department of Geosciences, National Taiwan University, Taipei, Taiwan, ROC

${ }^{6}$ Department of Geophysics, Stanford University, Stanford, USA

* Corresponding author address: Dr. Hiroki Sone, Department of Geophysics, Stanford University, Stanford, USA; E-mail: hsone@pangea.stanford.edu doi: 10.3319/TAO.2007.18.2.359(TCDP) 
a 1.1-m thick fault breccia zone and a $0.35-\mathrm{m}$ thick fault gouge zone. The fault zone at $1221 \mathrm{~m}$ consists of fault breccia and fault gouge of $1.15 \mathrm{~m}$ in total thickness. These are relatively harder and darker in color than the previous 2 fault zones. Each of the $\mathbf{3}$ fault zones contains a few layers of dark colored rocks of approximately $5 \mathbf{- 8 0} \mathbf{~ m m}$ in thickness within the fault breccia and fault gouge zones. These dark colored rocks were found distinctively within the fault rocks. However, there relation to the process of faulting is not clearly understood and shall be discussed in detail with the aid of microscopic observations.

(Key words: Chelungpu fault, Core description, Fault gouge, Fault breccia)

\section{INTRODUCTION}

The Taiwan Chelungpu-fault Drilling Project (TCDP) finished coring Hole-A successfully at a depth range of 500 to $2000 \mathrm{~m}$. Cores representing numerous fault structures were retrieved. Drilling started within the Cholan Formation, passed through the Chinshui Shale, and into the Kueichulin Formation. At regions within or close to the bottom of the Chinshui Shale and within the Kueichulin Formation, an increase in fault related deformations (fracture frequency) was encountered. This occurred at drilling depths between 1050 - 1250 and 1500 $1800 \mathrm{~m}$, respectively (Yeh et al. 2007). This is in keeping with seismic reflection surveys conducted prior to the drilling (Wang et al. 2002) that had predicted that the Chelungpu Fault should appear at a depth of around $1200 \mathrm{~m}$, and the Sanyi Fault approximately $800 \mathrm{~m}$ beneath that. The good correlation between the two results suggest that fault structures from the shallower group (1050 - $1250 \mathrm{~m})$ represent the Chelungpu Fault System, and the deeper fault structures represent the Sanyi Fault System.

The core recovery rate was well over 95\% and the quality of the cores was especially high for the shallower regions and detailed fault structures within the fault zone cores were observed clearly and continuously. Hole-B of the TCDP, drilled $40 \mathrm{~m}$ away from Hole-A at ground level, was aimed at recovering cores from $950-1350 \mathrm{~m}$. Thus a detailed description of the Chelungpu Fault System at Hole-A could be compared with the outcomes of Hole-B to understand the continuity of spatial distribution of fault structures. Here we focus on 3 major fault zones (referred as FZA1111, FZA1153, FZA1221; See Yeh et al. 2007) distributed at the shallower portion of the drilling; i.e., the section representing the Chelungpu Fault System. The distribution of deformation intensity is evaluated within the core depths from 1050 to $1250 \mathrm{~m}$, to get an overview of the deformation within the Chelungpu Fault System. Then detailed fault rock distribution within each fault zone based on mesoscopic core observations is presented. Also some observations made on half-cut fault zone cores are reported.

The depth values used in this article are restricted to the core depth evaluated from the length of drilling pipes inserted into the bore hole. At present, the amount of error caused by the stretch of drilling pipes due to their own weight is not evaluated. Thus these depths may be subject to correction in the future, if any known amount of deviation is to be found. 


\section{DISTRIBUTION OF DEFORMATION STRUCTURES (1050 - $1250 \mathrm{M})$}

Deformation structures observed at between 1050 to $1250 \mathrm{~m}$ were: fractures, fractures with displacement (minor faults), fractures with calcareous fillings, fault breccias, and fault gouges. Each structure that appeared within the cores was recorded individually in the on-site description, with their orientation, geometry, and thickness/aperture. By referring to these records and slab mode scan core images taken prior to packing procedures, deformation intensity was closely determined to depict the general structural trend within the Chelungpu Fault System.

To evaluate deformation intensity, a deformation intensity index, representing the degree of deformation, was assigned for each meter of core. The standards employed in assigning the index numbers are shown in Table 1. Deformation intensity can be determined using various definitions (i.e., fracture frequency, fracture volume percentage; Heermance et al. 2003). Our standard shown in Table 1 is defined by utilizing fracture frequency for the index numbers 0 - 4, while 5 - 7 reflects the amount of fine-grained matrix content in fault rock texture. Index 0 - 3 is assigned according to the number of fractures per meter of core, 4 is assigned for cores with

Table 1. Definition of the Deformation Intensity Index Numbers. The numbers to the left of the example core images are the represented depth points in Fig. 1.

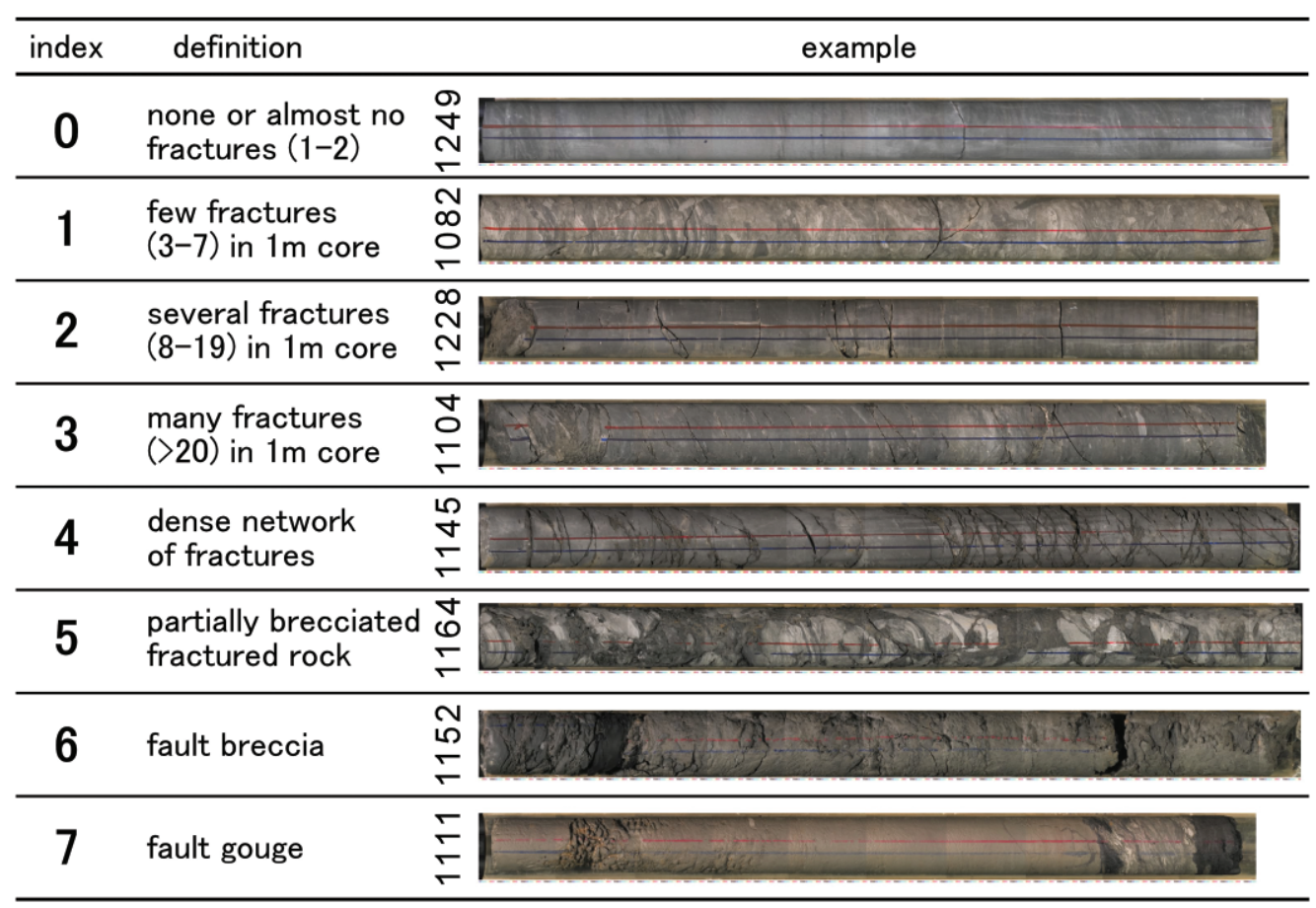


enough fracture frequency to create a web-like fracture network within the 8-cm core diameter. Index 5 is for heavily fractured rocks with enough shear deformation to detach and rotate rock fragments in parts of the rock mass. Cores are classified as index 6 when fragment detachment and rotation is achieved throughout the rock and therefore is fault breccia, and further comminution leads to index 7, a fault gouge. In addition to the structures covered above, thin individual breccia/gouge layers $(<2 \mathrm{~cm}$ thickness) were found in cores within index $1-3$. They were counted as single fractures, which is clearly an under-representation of deformation. However, since approximately $65 \%$ of the total fault rock volume was present within the 3 fault zones, we do not consider that as a serious underestimation in deformation intensity. Consequently, the index numbers do not represent a quantitative value, but they should simply describe the amount of deformation each 1-m segment of core has undergone.

Figure 1 represents the deformation intensity distribution relative to core depth. Each index number for a meter of core is plotted against its representing depth. The 3 regions with the highest deformation intensities are located at the three major fault zones where thick zones of fault breccias and fault gouges are distributed (see section 3 for details). From a depth of 1050 to about $1105 \mathrm{~m}$, a gradual increase in fracture is seen. After passing through the fault plane of the FZA1111, fractures suddenly decrease and a region with almost no fractures at

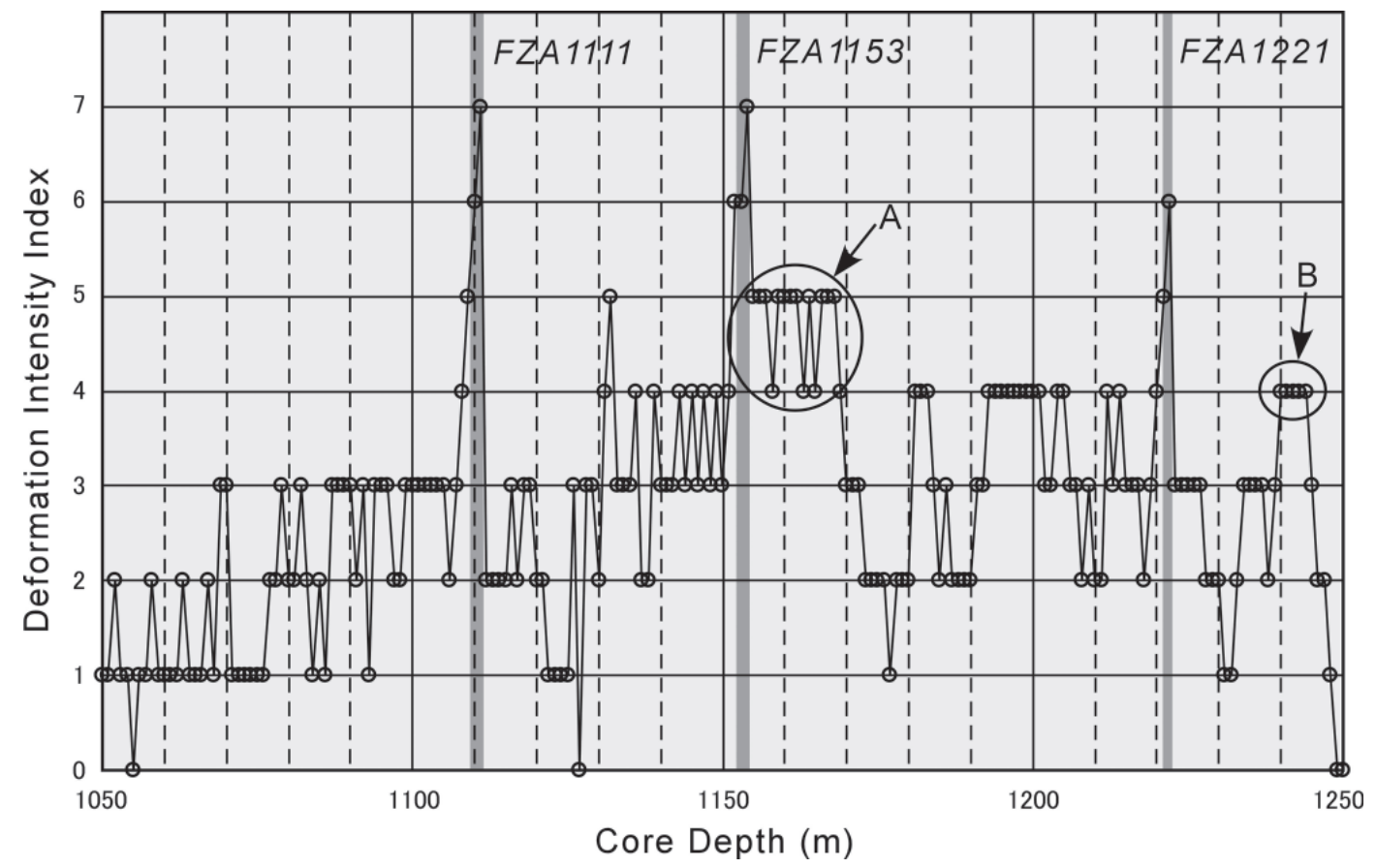

Fig. 1. Deformation Intensity Indexes plotted against the corresponding depths. The vertical shadows represent the positions of the fault zones. 
around $1125 \mathrm{~m}$ is found. The deformation observed in this range (1050 - $1125 \mathrm{~m})$ may be related to the faulting of FZA1111, since deformation intensity simply rises (lowers) when approaching (receding) from the fault plane. This pattern is seen again at the hanging-wall and the foot-wall of FZA1153, however, on the foot-wall side, there is a region of high deformation (Fig. 1a, $1155-1168 \mathrm{~m}$ ) before the deformation intensity drops rapidly. From the on-site description, the orientations of the fractures and breccia layers in this highly deformed region were nearly vertical against the horizon (strike/dip; N70 - 90W/80 - 100N). This is in contrast to the nearly bedding parallel (strike/dip; N15E/30E) structures observed in the nearby region. Whether this high deformation intensity region belongs to the FZA1153 or not is unknown at present.

Less variation in deformation intensity is seen between $1180-1250 \mathrm{~m}$ than at $1050-1180 \mathrm{~m}$. That is, the deformation intensity index is mostly within $2-4$, except for the high deformation intensity region at FZA1221. From the on-site description, fractures in the lower half region $(1180-1250 \mathrm{~m})$ were generally observed to be more intact, in addition to an increased prevalence of fractures filled with calcareous minerals. It is also worth noting that at around $1242 \mathrm{~m}$ (Fig. 1b), a series of black seams were found (see Yeh et al. 2007), and some deformed rocks from this region were completely cohesive cataclasites.

\section{DISTRIBUTION AND DESCRIPTION OF FAULT ROCKS IN FZA1111, FZA1153, AND FZA1221}

In this section, a detailed description of the 3 fault zones (FZA1111, FZA1153, FZA1221) in the Chelungpu Fault System is presented. In Figs. 2, 3, and 4, the schematic diagram of the fault rock distribution is shown accompanied with slab mode scan core images (except for Run 378 section 2). The schematic diagrams were drawn by tracing the slab mode scan images and referring to sketches taken on-site. The numbers to the left side of the core images represent the top depths for each core section (black numbers) and the bottom depths of each drilling run (gray numbers). These core depths are "corrected" core depths, which are different from the core section depths recorded in the Drilling Information System (DIS) (see Appendix). The blue and red lines on the core images were drawn on-site for the identification of the bedding dip direction, each supposedly representing N105E (local bedding dip direction) and N85E, respectively. The structural classifications are shown between the core images and schematic diagrams. To the right side of the diagrams are additional descriptive comments on the structural features of the fault zone cores.

The terminologies used for the classification of fault rocks were based on the definitions given by Sibson (1977), with amendments for foliated rock types produced in cataclasis (Chester et al. 1985). However, the term "black material" does not follow Sibson's definition for such dark colored rocks, but is used to refer to material that was difficult to determine as fault rocks by direct observation of the core. The words "width" and "thickness" refer to different aspects. "Width" represents the core length where a certain structure/layer is distributed, while "thickness" refers to the normal distance across a certain planer structure/layer. Grain sizes are described according to Wentworth's scale. 

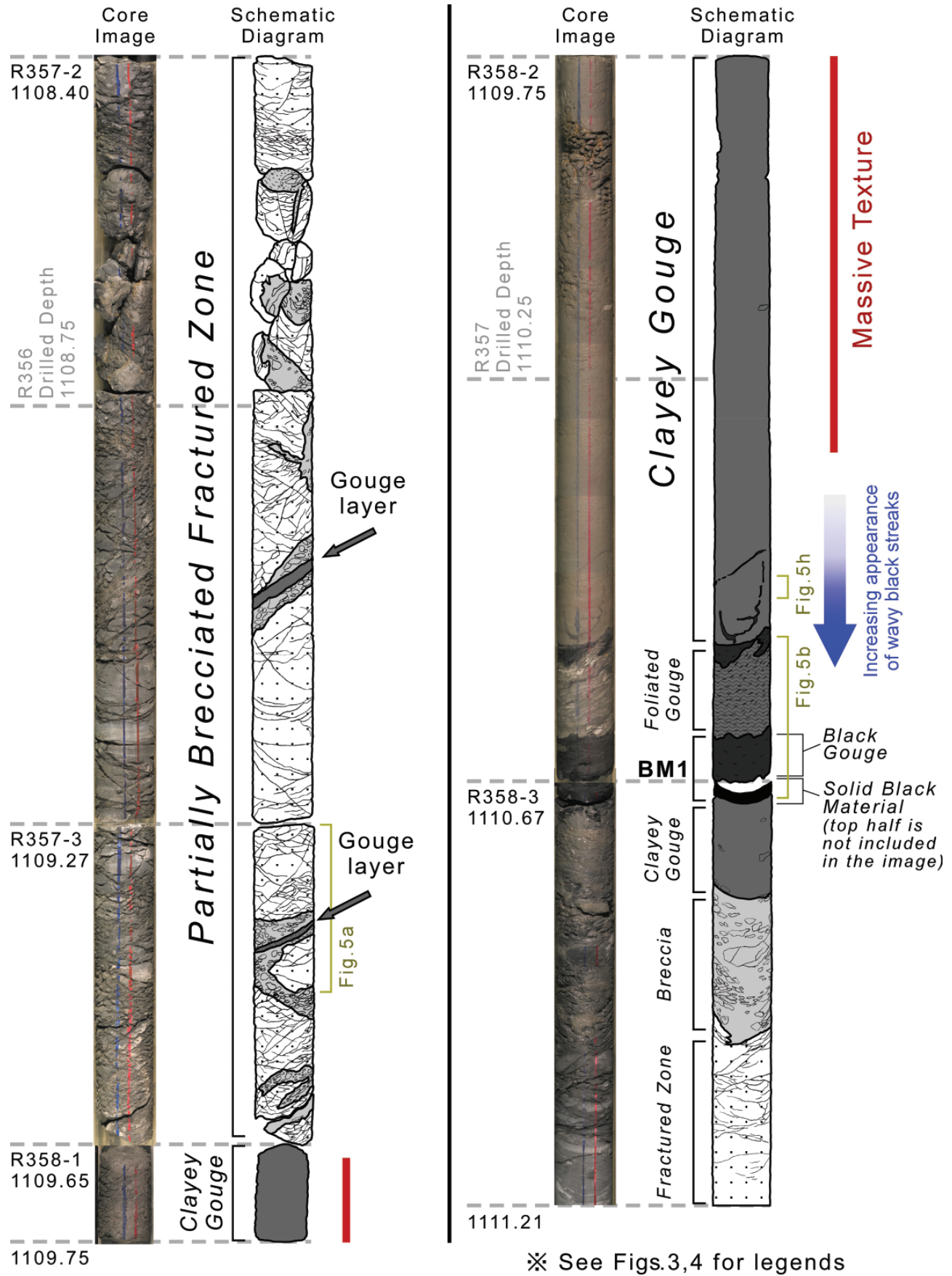

Fig. 2. Core Image and Schematic Diagram of FZA1111 with descriptive comments. Core width is approximately $8 \mathrm{~cm}$. The blue lines indicate the bedding dip direction. 
Sone et al.

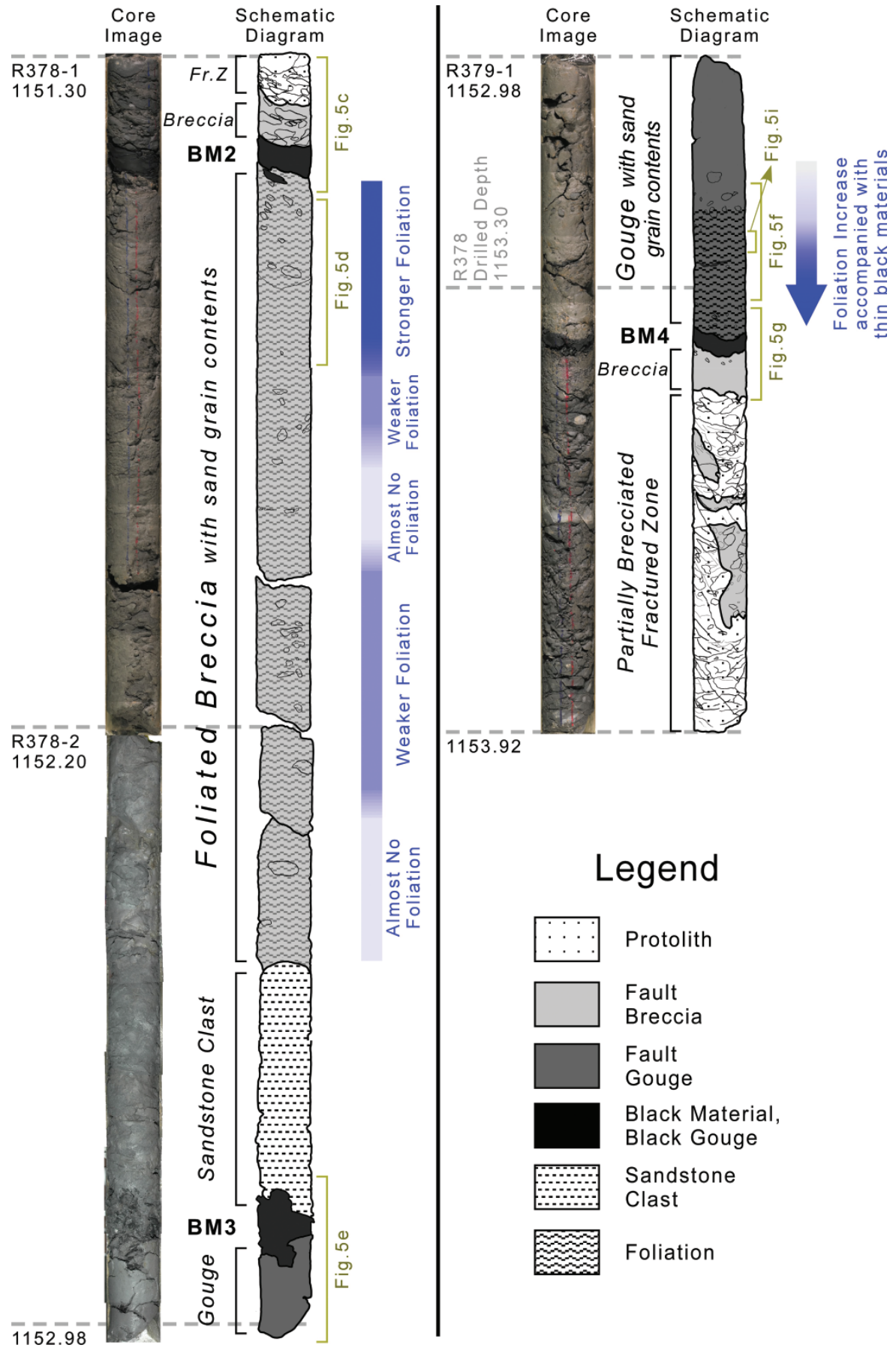

Fig. 3. Core Image and Schematic Diagram of FZA1153 with descriptive comments. 


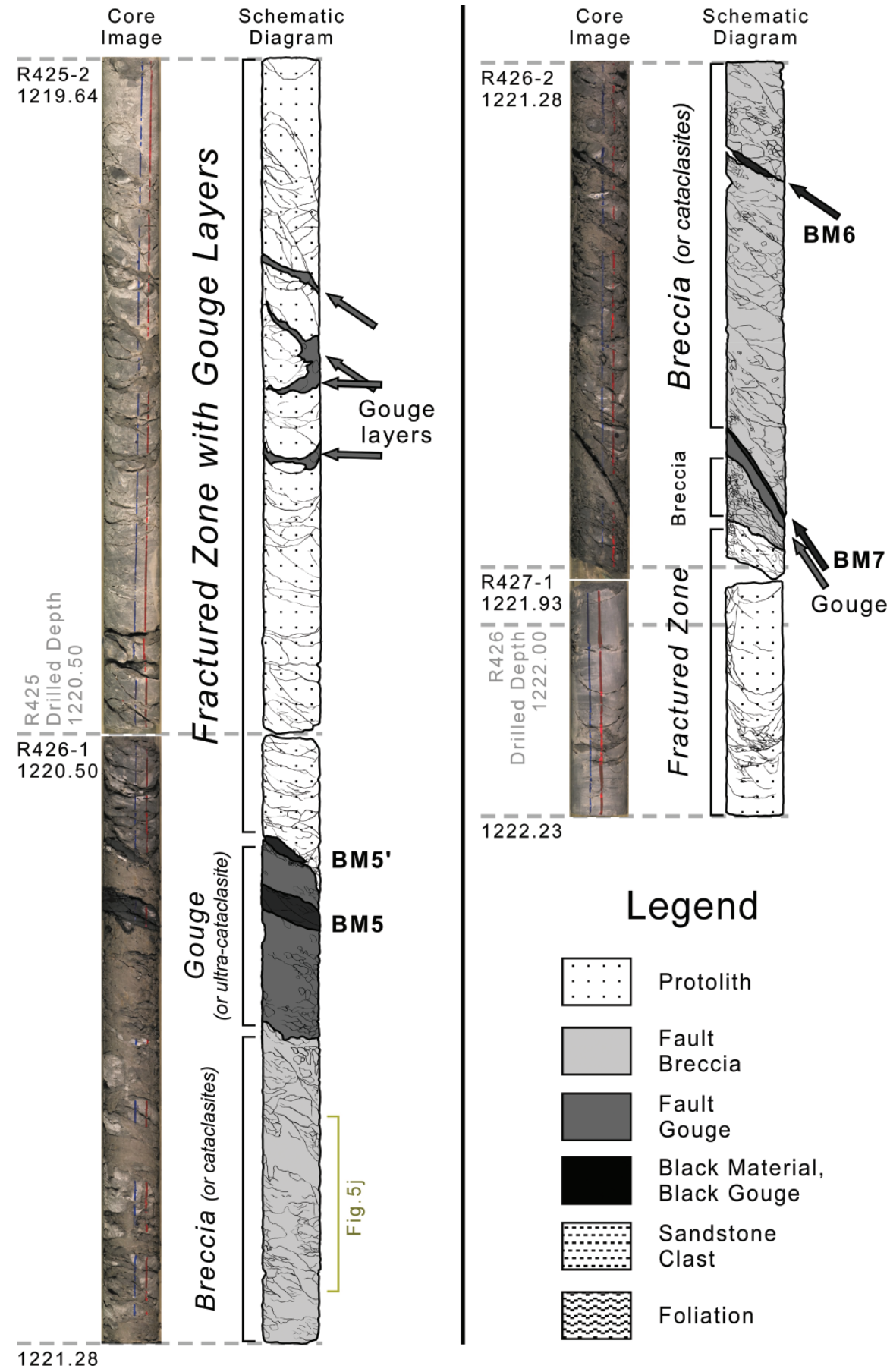

Fig. 4. Core Image and Schematic Diagram of FZA1221 with descriptive comments. 
Additional photographs of the fault zone cores are also shown in Fig. 5 to help view the textures. Some of these photos are half-cut core surfaces.

\subsection{FZA1111}

Figure 2 covers a depth range of between $1108.40-1111.21 \mathrm{~m}$. The fault is bedding parallel and the fault zone generally consists of a partially brecciated fractured zone of $1.25 \mathrm{~m}$ in width and has a light gray clayey fault gouge zone of $1.1 \mathrm{~m}$ in width (corresponding to about 1.15 and $1.05 \mathrm{~m}$ in thickness, respectively, for a 20-degree bedding parallel fault dip). "Black gouge/material" (BM1) was found close to the bottom of the fault core region, and after passing this "black material", transition to the foot-wall host rock was rapid.

A continuous increase in fracture frequency toward the fault zone from the hanging-wall side leads to a nearly brecciated fracture zone. Several minor concentrations of deformation are seen within this region, forming several-centimeter thick gouge layers. This region may appear like a "breccia zone" instead of a "fracture zone" due to its highly deformed nature. But each fragment was still in its original position and had not been subject to segregation or rotation, hence classified as "fracture zone" (Fig. 5a).

From $1109.65 \mathrm{~m}$ down, a wide zone of soft, light gray clayey gouge appears. The boundary at the transition from the fractured zone to the clayey gouge is not preserved since it is also the boundary of the coring runs 357 and 358 . The grain size of the gouge content is silt and clay. No foliation or structures with preferred orientation was observed from the core surface of this gouge zone and the texture appeared to be almost completely massive. Only a few rounded sandstone fragments, up to $5 \mathrm{~mm}$ in diameter, were found (Fig. $5 \mathrm{~h}$ ). Note that the rough core surface around 1109.80 - 1110.00 m corresponds to where the core was "miss-caught" from coring run 357 . The soft gouge cores from 1109.65 to $1110.25 \mathrm{~m}$ survived two coring runs, and the rough surface is thought to have been produced by the extra mud circulation they underwent compared to the surrounding regions (see Appendix). Observations on half cut cores show that the inner texture of this distracted region is no different from the surrounding clay gouges. However, from about $1110.40 \mathrm{~m}$ down, the massive texture becomes slightly distracted by some thin wavy streaks of dark colored, or black, gouge. These black streaks increase until it reaches a patch of black colored gouge $(<2 \mathrm{~cm}$ in thickness) at the top of the next structural section.

The foliated gouge has a mixed wavy texture consisting of white to nearly black colored gouge layers with weakly defined boundaries (Fig. 5b). The foliation was estimated to be nearly parallel to the bedding plane of the host rocks by comparing the edges with the adjacent section. The foliated gouge abruptly turns black at the bottom $(1110.60 \mathrm{~m})$, sharing an irregular boundary with the black gouge underneath. The black gouge was also found to be somewhat foliated, and many black fragments/grains smaller than $2 \mathrm{~mm}$ were found within. These black fragment/grains were also found within the above foliated gouge as well, especially close to the patch of black gouge at the top, but the fragment/grains were much smaller in size.

A 2-cm thick hard layer of "black material" was found at the bottom of the black gouge, which had naturally split into two discs after recovery, and slicken-lines were observed on the split surfaces (Fig. 5b). The black material discs appeared to be massive and uniform in texture, 

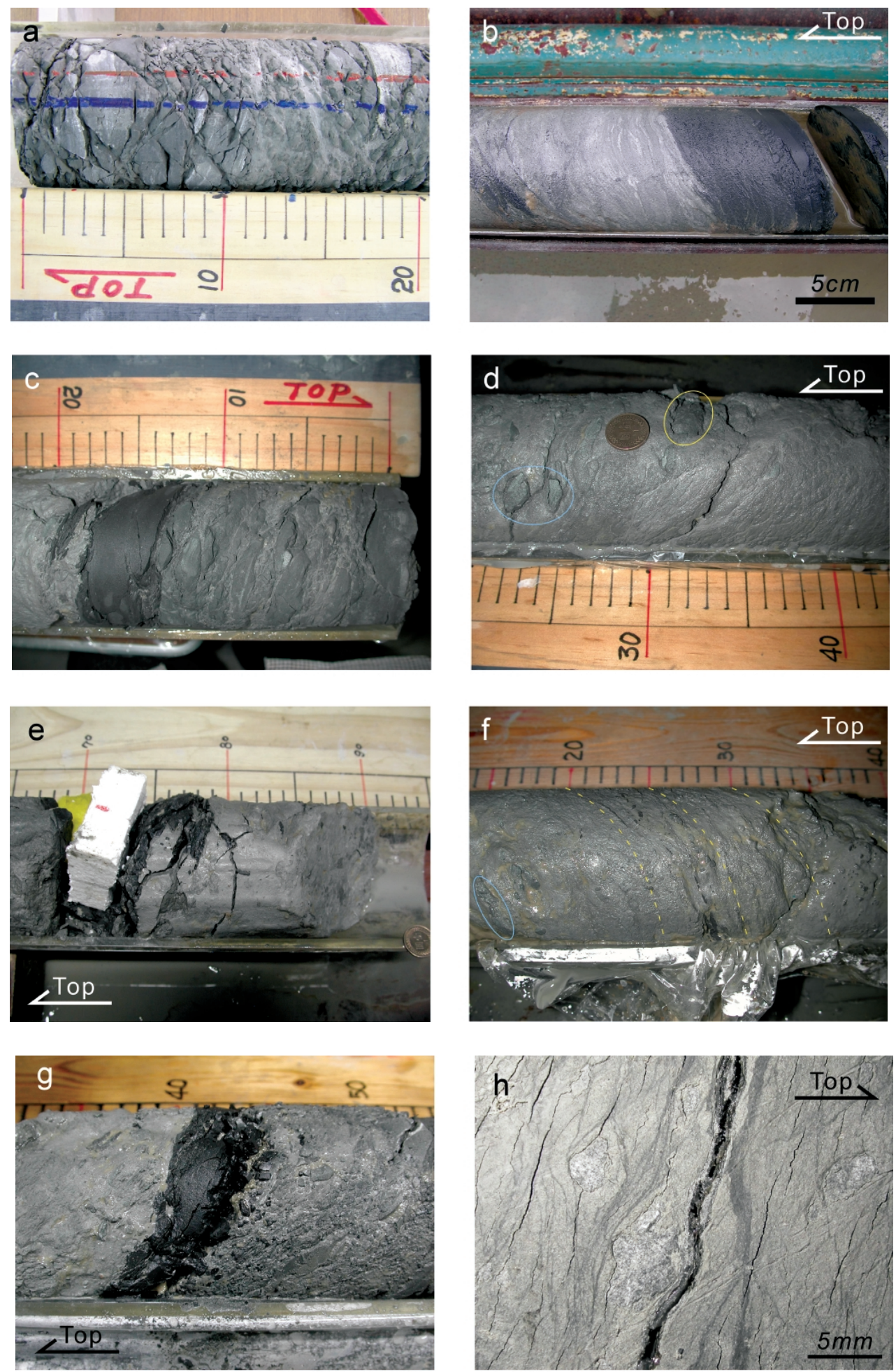

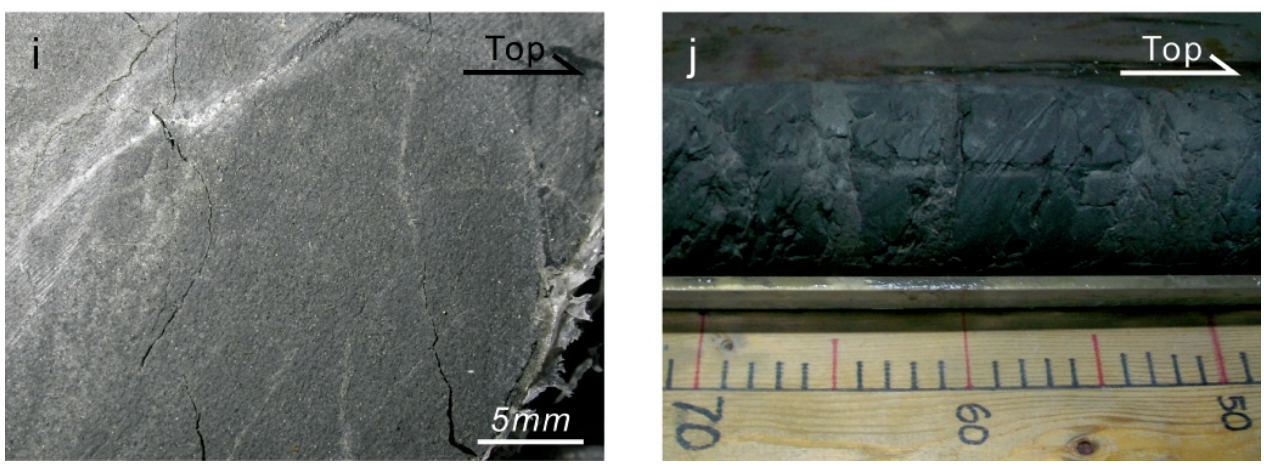

Fig. 5. Photographs of fault zone whole cores (a, b, c, d, e, f, g, j) and half-cut surfaces (h, i). The corresponding locations are sited in Figs. 2, 3, and 4. (a) Photograph of the partially brecciated fractured zone. Lower half of the core in the photograph is brecciated. (b) Photograph of the foliated gouge and BM1 taken at the drilling platform immediately after recovery. The black material has naturally split into 2 discs and slicken-lines were observed on the split surface. (c) Photograph of the BM2 and its surrounding regions. The dark colored BM2 is abruptly inserted between the 2 breccia zones above and below BM2. The difference in color and texture of the 2 breccia zones, above and below, could also be seen. (d) Photograph of the foliated breccia zone with sand-grain contents in FZA1153. The weakly foliated texture could be seen, and the blue and yellow circles indicate some examples of Type 1 and 2 clasts, respectively. (e) Photograph of BM3 and the gouge zone underneath. The inserted Styrofoam block was an attempt to avoid the fragments from collapsing to best preserve its original structure. (f) Photograph of the foliated gouge zone with sand-grain contents in FZA1153. Yellow dotted lines indicate the direction of the foliation. Thin discontinuous layers of black material could be seen within the foliation. (g) Photograph of BM4 and its surrounding regions. The slight roughness of the surface texture compared to BM1 (black discs) could be seen. Again, the difference in color and texture of the 2 breccia zones, above and below, could also be seen. (h) Half-cut surface of the clayey gouge zone in FZA1111 close to the foliated gouge zone. The dark shadowed aperture is due to the epoxy resin that permeated into open cracks. Small round size sandstone clasts and many dark colored steaks could be seen. (i) Half-cut surface of the gouge with sand grain contents in FZA1153. Presence of sandy-silty grains could be seen, which is not found in Fig. 5h. (j) Photograph of the breccia zone in FZA1221. Rock fragment size is larger in this breccia zone and the color is darker compared to fault rocks from the other 2 fault zones. 
and the drilled surface was smooth. Below the hard black material is a sharp contact with another light gray clayey gouge layer. The clayey gouge gradually changes into fault breccia toward the fractured foot-wall host rock as it loses its matrix content. At the bottom end of the core in Fig. 2, the fracture frequency has dropped rapidly to the point where only several fractures are found.

\subsection{FZA1153}

Figure 3 covers a depth from 1151.30 to $1153.92 \mathrm{~m}$. FZA1153 is bedding parallel and generally consists of a 1.20 -m wide foliated breccia zone and a $0.40-\mathrm{m}$ wide gouge zone (corresponding to about 1.1 and $0.35 \mathrm{~m}$ in thickness, respectively, for a 20-degree bedding parallel fault dip). Some features contrasting with FZA1111 were that the fault rocks contained some sand grains (very fine sand to coarse silt) in the matrix content, and that several possible regions of black materials were found (Fig. 3, BM2, 3, 4). During the process of cleaning drilling mud off the core surface, it was apparent by touching the core surface that these sand grains existed within the fault rocks and were also observed in the surface of the half cut cores (Figs. 5h, i) ("with sand-grain contents" after the fault rock type notes sand grain presence).

The fractured hanging wall rock continues from the above depths to the top of Fig. 3. The fracture zone exhibits progressively some matrix content and forms a 5 -cm breccia layer. Below the breccia, a 4-cm thick, hard, dark solid material (BM2) suddenly appears, with orientation nearly parallel to the bedding plane (Fig. 5c). The surface texture of BM2 seems to be rough compared to BM1. The bottom boundary of BM2 is also abrupt and makes contact with a region of widely distributed gray foliated breccia with sand-grain contents.

The foliated breccia zone with sand-grain contents has a different texture from the breccia layer above BM2 in that, rock fragments are much softer and the fragments have vague boundaries. The foliated breccia zone mainly consists of soft gray sandstone fragments (Type 0 ), which occupy more than $70-80 \%$ of the total rock mass, and spaces between the fragments are filled by gray sandy/silty matrix contents. It appears as though each soft angular sandstone fragment $(1-10 \mathrm{~mm}$ size) is separated by millimeter thin matrix layers (Fig. 5d). Within this breccia zone, 2 different clasts to those of Type 0 were distributed (both $<5 \%$ rock mass). The first type exists more in the shallower portion (Type 1) and the second type more towards the bottom of the breccia zone (Type 2). Type 1 clasts are sub-angular hard sandstone fragments, usually up to 10 to $20 \mathrm{~mm}$ in length and bluish gray in color due to calcareous content. Similar sandstone types were found intermittently in the host rock region during the onsite description process, especially at regions deeper than the Chelungpu Fault System. Type 2 clasts are similar to Type 0 soft gray sandstone fragments, but are more rounded and larger, approximately 10 $30 \mathrm{~mm}$. The breccia zone overall is weakly foliated and the degree of foliation fluctuates rapidly within the 1.20 -m wide breccia zone (Fig. 3, blue gradational bar).

From the bottom of the foliated breccia with sand-grain contents, there is a sandstone layer about $30 \mathrm{~cm}$ wide. It may be quite unusual to see an undamaged rock layer in the middle of a fault zone, so it is believed that the drilling has coincidently passed through a large size clast. From the bottom of this sandstone clast $(1152.80 \mathrm{~m})$ to the end of the coring run 379 
$(1152.98 \mathrm{~m})$, the core was inevitably destroyed when being removed from the core barrel, and its structure is not preserved so well. However it is evident that a region of black material (BM3) was present, after the sandstone clast, from the broken pieces of solid hard black materials (Fig. 5e). After BM3, a gouge zone appears that continues to the top of the next section, and to a depth of about $1153.37 \mathrm{~m}$.

The gouge zone with sand-grain contents appears to be quite similar to the foliated breccia zone above, in that the gray color is nearly identical, Type 1 clasts are found, and there are like sand grains found in the matrix (Fig. 5f). However the visible fragments are much smaller in this gouge zone and the fraction of the matrix content is more dominant. The texture of the gouge-zone is random at the top, but some foliation appears from $1153.20 \mathrm{~m}$ down and increases towards the bottom. As foliation increases within the gouge-zone, some black materials are evident within the foliations. The presence of these small amounts of black material either occur as small black material fragments inserted within foliations or as thin black material layers of less than $1 \mathrm{~mm}$ in thickness (Fig. 5f). However, it is unclear whether these are continuous structures or not from core surface observations. The next black material (BM4) is then found at the bottom of the gouge-zone. BM4, as in BM2, has a slight rough surface texture compared to BM1. However, it is darker than BM2, and may possibly be softer and fragile, judging from the black material fragments scattered on the core surface (Fig. $5 \mathrm{~g}$ ).

Immediately below the BM4 is a thin breccia zone that contrasts with the fault rocks with sand-grain contents found above (Fig. $5 \mathrm{~g}$ ). In this breccia zone, less sand grains were found and rock fragments were hard. The matrix content within the breccia is gradually lost, and it becomes a partially brecciated fracture zone. This highly deformed fractured zone continues for more than $10 \mathrm{~m}$, which corresponds to the high deformation intensity region below FZA1153 in Fig. 1 position A.

\subsection{FZA1221}

Figure 4 covers a depth from 1219.64 to $1221.23 \mathrm{~m}$. FZA1221 is characterized by a $1.25 \mathrm{~m}$ width fault rock region accompanied by several layers of black material and a thin sharp high angle fault plane consisting of gouge and black material close to the bottom $(1.15 \mathrm{~m}$ in thickness assuming a 20-degree bedding parallel fault dip). Some contrasting features of the FZA1221 compared to FZA1111 and FZA1153 are that: 1) the orientation of the structures is not clearly defined and they seem to be dipping between an easterly (bedding parellel) to northern direction; and 2) fault rocks are harder and darker (Fig. 5j). From the onsite description, it is apparent that fractures and other deformation structures encountered after around $1200 \mathrm{~m}$ are more intact than those of the shallower regions. Thus these fault rocks in FZA1221 could be described as "cataclasites" instead of breccia/gouge owing to their partial cohesiveness. However, the degree of cohesiveness required to describe cataclasites is somewhat arbitrary, and consequently here they are referred to as gouges and breccias.

Host rocks with nearly intact fractures continue into the region above Fig. 4, and hard gouge layers are found when approaching FZA1221. The fracture zone with gouge layers appears at 1219.64 - $1220.65 \mathrm{~m}$ of Fig. 4. From 1220.65 to $1221.90 \mathrm{~m}$, fault rocks are distributed. In the top $0.25 \mathrm{~m}$ of the fault rock region $(1220.65-1220.90 \mathrm{~m})$ is a gouge zone, in which a 
3-cm thick black material layer (BM5) is found. There was also a small discontinuous piece of black material (BM5') close to the boundary of the fracture zone and the gouge zone. This piece may have been carried away from its original position by the high angle fracture that is apparent in the back side of the core image in Fig. 4. The amount of rock fragments increases and the breccia zone starts from $1220.90 \mathrm{~m}$. The breccia zone contains larger size rock fragment clasts compared to the previous breccia zones encountered in FZA1111 and FZA1153. The orientation of the shear plane within the breccia zone is not clear, but the general orientation of the fractures suggests a parallel structure with the above gouge zone and BM5. Also a thin layer of black material (BM6, $<5 \mathrm{~mm}$ ) was found at around $1221.40 \mathrm{~m}$, also parallel to the general orientation of the fractures.

The bottom of the breccia zone is cut by a sharp high angle fault plane. The fault plane consists of an approximately 5-mm thick black material layer (BM7) and a 2-cm thick gouge layer beneath it. After this sharp structure follows a small breccia zone of $5-10 \mathrm{~cm}$ in width, and finally the fractured foot-wall rock appears.

\section{OBSERVATIONS ON SURFACES OF HALF CUT BLACK MATERIALS}

Some selected regions within FZA1111 and FZA1153, most including the black materials, were cut in pieces for sample distribution. They were first fixed by covering with epoxy resin, and then cut parallel to the core axis. Information about the exact orientation of the split surfaces is lacking, and the epoxy resin had permeated into some openings making some structures difficult to distinguish. However the split surfaces still resembled some structural characteristics. Photographs and sketches with interpretations are presented in Fig. 6.

Figures $6 \mathrm{a}$ and $\mathrm{b}$ show the half-cut surface of BM1. The photograph includes the whole of the black gouge to its upper boundary with the foliated gouge. The hard "black disc" of black material at the bottom of BM1 is not included in the figures, since it was kept out from the cutting procedure. Figures $6 \mathrm{c}$ and d show the half-cut surface of BM4. The photograph includes the foliated gouge above BM4 and the breccia region below BM4. Epoxy resin has penetrated into some openings, and thus, some areas are not observed clearly.

It is seen from both surfaces that: (1) transition from the above gouge zones to the black gouge/material regions is not gradual, but characterized by a clear boundary between the constituents; (2) pieces of non-black materials are present within the black gouge/material region, and vice versa; (3) black gouge/material is present in narrow spaces between nonblack material fragments.

\section{SUMMARY AND DISCUSSION}

The main descriptive features revealed from the structural observations of fault zone cores in this article are: 1) Fault rocks distributed within the Chelungpu Fault System were concentrated within the 3 fault zones FZA1111, FZA1153, and FZA1221 where fault rock zones over $1 \mathrm{~m}$ in width were encountered; 2) A slight difference in the composition of the fault rocks in FZA1111 and FZA1153 was observed in that, the matrix content of FZA1111 was silty/clayey 
whereas the matrix of very fine sand to coarse silt grains were found consistently within the silty/clayey matrix content of the fault rocks in FZA1153; 3) Deformation structures observed in the deeper half of the Chelungpu Fault System (1180 - $1250 \mathrm{~m})$ were more cohesive compared to those of the shallower region; 4) Some distinctively dark colored rocks (black gouge/ materials) were found within the fault rocks of the 3 fault zones; 5) The appearance of foliation and traces of thin black material layers/streaks increased toward the black materials for BM1 and BM4, and possibly for BM2; 6) Black material/gouge regions contained non-black mate-
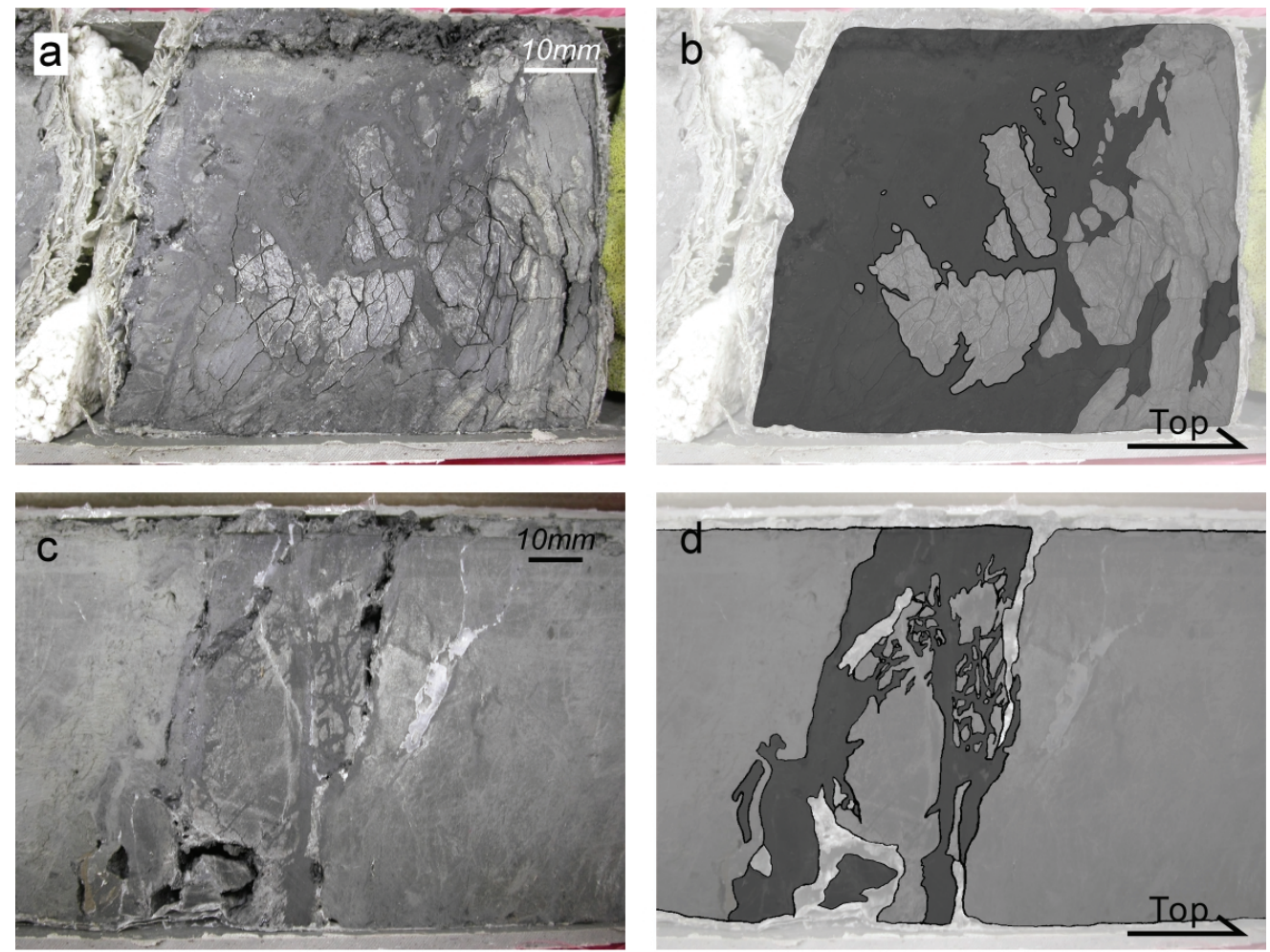

\section{Legend}

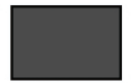

\section{Black Gouge/ Material Region}

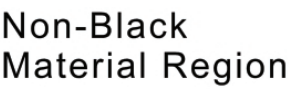

Fig. 6. Photographs and schematic diagrams of half-cut surfaces of the half-cut black materials. (a) Photograph of the half-cut surface at BM1, but not including the hard solid black material disc found at the bottom of BM1. (b) Sketch of the boundary between the foliated gouge and the black gouge. (c) Photograph of the half-cut surface at BM4. (d) Sketch of the boundary between the nearby gouge/breccia and the black material. 
rial (gouge or breccia) pieces within themselves and black materials/gouges were present in narrow space between non-black material pieces.

In the core description from the shallow drilling of Chelungpu fault (Tanaka et al. 2002), fault rock zones over $0.5 \mathrm{~m}$ wide were found at more than 10 locations, both in the Northern Borehole and the Southern Borehole. However as described in this article, distribution of wide fault rock regions exceeding $0.5 \mathrm{~m}$ in width were only found at the 3 identified fault zones from the TCDP Hole-A. Deformation structures were more concentrated to selected regions possibly due to the fact that the Chelungpu fault was penetrated at greater depth. It is convincing that the approximately $8 \mathrm{~m}$ coseismic slip of the 1999 Chi-Chi earthquake (Ma et al. 2000) took place within the 3 fault planes encountered, and examination of these faults may provide insights about the mechanical features of the earthquake.

A pronounced feature of the 3 fault zones found in the Chelungpu Fault System is the presence of dark colored rocks, so called the "black materials". The fact that these rock types were only found within the 3 fault zones, but not in the host rock regions, indicates that they were likely produced by a mechanical and/or chemical process characteristic within fault zones. Yue et al. (2005) shows that the 1999 Chi-Chi slip plane underlying the TCDP drilling site lies along the "newly-propagated North Chelungpu Chinshui detachment" which accounts for up to $0.3 \mathrm{~km}$ of slip displacement out of $15 \mathrm{~km}$ of total slip along the Chelungpu fault. Assuming a 20 - 30 degree fault dip continuing downward, this $0.3 \mathrm{~km}$ displacement would correspond to about $0.1-0.15 \mathrm{~km}$ relative depth difference between the hanging and foot-wall caused by this newly-propagated fault. If the assumptions are correct, this means that the black materials found in FZA1111, 1153, and 1221 are likely to represent deformation mechanisms and/or chemical processes characteristic of the depth range between $1.1-1.4 \mathrm{~km}$, usually understood to be within the clay gouge regime or possibly at the upper end of the cataclasite regime (Scholz 1988; Sibson 2003).

Mesoscopic observation reveals that some of the black materials (BM1, BM2, BM4, and BM7) construct a discontinuous boundary between the upper and lower fault rock regions that may possibly suggest a considerable amount of displacement within or above/below the black materials. A direct evidence of shearing was the slicken-lines observed on the split surface of the hard black material in BM1 (Fig. 5b). Also foliations tend to increase towards BM1 and BM4, accompanied by the appearance of black streaks and thin black-material-containing layers. Increases in foliated fault rock types when approaching the principle slip zone is observed in other shallow crustal faults as well (Chester and Logan 1986; Evans and Chester 1995) and they may be indicative of increasing strain (Scholz 2002) towards the principle slip zone. Coupled with the common understanding that coseismic shearing localizes to principle slip zones of less than $10 \mathrm{~cm}$ or even less than $1 \mathrm{~cm}$ thickness within the fault core region (Sibson 2003), one can imagine that the black materials are products of intense coseismic shearing.

However, our mesoscopic observations alone do not confirm such possibilities. The kind of slicken-lines observed on the surface of BM1 was found repeatedly on numerous fractures with negligible amounts of displacement within the host sedimentary rocks. Observations on some half cut surfaces of BM1 and BM4 (Fig. 6) may suggest some mechanical mixing of the 
black and non-black constituents, and possibly indicate some material property contrasts between them based on there difference in occurrence by means of fragment shape. However, a sharp plane that could represent a spatially continuous slip localized zone was not found. Moreover, even if the dark materials may have received deformation by shearing, shearing may not be the cause of coloration of these dark colored materials. Thus the relation between the black materials and faulting, or shearing, still remains a question. Detailed observations on microstructures shall be conducted for each of the black materials discovered in order to detect any clear indication of shearing and to search for clues to better understand how the dark material obtains its color. Such observations could be critical in interpreting the future outcomes of chemical/physical analyses conducted on fault rock samples.

Acknowledgements We express our sincere gratitude to the Principal Investigators of the TCDP including Prof. Ji-Hao Hung, Kuo-Fong Ma, Yi-Ben Tsai, and Chien-Ying Wang (National Central University), and Prof. Sheng-Rong Song (National Taiwan University) for letting us take part in this project and supporting us. The article benefited from many helpful discussion and comments on the manuscript by Prof. Akito Tsutsumi (Kyoto University), and ideas shared on-site with Tetsuro Hirono, Weiren Lin (JAMSTEC), and Prof. Hidemi Tanaka (Tokyo University). Comments by anonymous reviewers helped to improve this article greatly. In addition, we greatly appreciate the help out of Taiwanese assistants and students who were always very friendly and supportive during our stay in Taiwan.

\section{REFERENCES}

Chester, F. M., M. Friedman, and J. M. Logan, 1985: Foliated cataclasites. Tectonophysics, 111, 139-146.

Chester, F. M., and J. M. Logan, 1986: Implications for mechanical properties of brittle faults from observations of the Punchbowl fault zone, California. Pure Appl. Geophys., 124, 79-106.

Evans, J. P., and F. M. Chester, 1995: Fluid-rock interaction in faults of the San Andreas system: inferences from San Gabriel fault rock geochemistry and microstructures. $J$. Geophys. Res., 100, 13007-13020.

Heermance, R., Z. K. Shipton, and J. P. Evans, 2003: Fault structure control on fault slip and ground motion during the 1999 rupture of the Chelungpu fault, Taiwan. Bull. Seismol. Soc. Am., 93, 1034-1050.

Ma, K. F., T. R. Song, S. J. Lee, and H. I. Wi, 2000: Spatial slip distribution of the September 21, 1999, Chi-Chi, Taiwan earthquake $\left(\mathrm{M}_{\mathrm{w}}\right.$ 7.6)-Inverted from teleseismic data. Geophys. Res. Lett., 27, 3417-3420.

Scholz, C. H., 1988: The brittle-plastic transition and the depth of seismic faulting. Geol. Rundsch, 77, 319-328.

Scholz, C. H., 2002: The mechanics of earthquake and faulting, Camb. Univ. Press, 135-145.

Sibson, R. H., 1977: Fault rocks and fault mechanisms. J. Geol. Soc. London, 133, 191-213. 
Sibson, R. H., 2003: Thickness of the seismic slip zone. Bull. Seismol. Soc. Am., 93, 1169-1178.

Tanaka, H., C. Y. Wang, W. M. Chen, A. Sakaguchi, K. Ujiie, H. Ito, and M. Ando, 2002: Initial science report of shallow drilling penetrating into the Chelungpu fault zone, Taiwan. Terr. Atmos. Ocean. Sci., 13, 227-251.

Wang, C. Y., C. L. Li, F. C. Su, M. T. Leu, M. S. Wu, S. H. Lai, and C. C. Chern, 2002: Structural mapping of the 1999 Chi-Chi earthquake fault, Taiwan by seismic reflection methods. Terr. Atmos. Ocean. Sci., 13, 211-226.

Yeh, E. C., H. Sone, T. Nakaya, K. H. Ian, S. R. Song, J. H. Hung, W. Lin, T. Hirono, C. Y. Wang, K. F. Ma, W. Soh, and M. Kinoshita, 2007: Core description and characteristics of fault zones from Hole-A of the Taiwan Chelungpu-fault Drilling Project. Terr. Atmos. Ocean. Sci., 18, 327-357, doi: 10.3319/TAO.2007.18.2.327(TCDP).

Yue, L. F., J. Suppe, and J. H. Hung, 2005: Structural geology of a classic thrust belt earthquake: The 1999 Chi-Chi earthquake Taiwan $\left(\mathrm{M}_{\mathrm{w}}=7.6\right)$. J. Struct. Geol., 27, 20582083.

Sone, H., E. C. Yeh, T. Nakaya, J. H. Hung, K. F. Ma, C. Y. Wang, S. R. Song, and T. Shimamoto, 2007: Mesoscopic structural observations of cores from the Chelungpu Fault System, Taiwan Chelungpu-fault Drilling Project Hole-A, Taiwan. Terr. Atmos. Ocean. Sci., 18, 359-377, doi: 10.3319/TAO.2007.18.2.359(TCDP).

\section{APPENDIX}

The depths recorded in the DIS solely rely on the drilled depth ranges of each run (each trial for drilling and retrieving cores), ignoring the shortfall/excess of the retrieved core. That is, the top depth of the retrieved cores in each run was always matched with the top depth of where the drilling restarted in each run. However, drilled cores were not always recovered completely in the designated coring run, and unrecovered cores from previous coring runs are sometimes retrieved in the later coring run. This kind of situation occurs especially at fault zone regions, where "catching" of the soft fault rocks could be a challenging process. Thus in some cases, it is proper to match the bottom depth of the retrieved cores with the depth where drilling stopped in a coring run. The recorded depth in the DIS therefore has some overlap in core depth, particularly within the fault zones, resulting in cores with identical depth ranges. When arguments are done on properties that change by centimeters, there may be confusion in distinguishing cores from these overlapped depth ranges.

Depth corrections were made on core depths around the 3 fault zones argued in this article to avoid the confusions explained above (Table 2). Since the total recovered length of the drilled cores nearly summed up to the total drilled depth around the fault zones, each core section depths were re-assigned so that a particular section bottom depth would also become the section top depth of the next core section. The corrected values are used in Figs. 2, 3, 4 (black numbers). Consequently, the relative position of where the drilling bit reached in each coring run (gray numbers in Figs. 2, 3, 4) could be identified on the core surface. This helps to recognize the drilling induced structures on the core surfaces. 
Table 2. Corrected core section depths used in this article. Values in the "Recorded" column are the values recorded in the DIS, and values in the "Corrected" column are the re-assigned values used in this article.

\begin{tabular}{ccc}
\hline \multirow{2}{*}{ Run-Sec. } & \multicolumn{3}{c}{ Depth (m) } \\
& Recorded & Corrected \\
\hline $356-1$ & 1106.75 & 1106.75 \\
& 1107.49 & 1107.49 \\
$356-2$ & 1107.49 & 1107.49 \\
& 1108.14 & 1108.14 \\
& & \\
$357-1$ & 1108.75 & 1108.14 \\
& 1109.02 & 1108.40 \\
$357-2$ & 1109.02 & 1108.40 \\
& 1109.99 & 1109.27 \\
$357-3$ & 1109.99 & 1109.27 \\
& 1110.38 & 1109.65 \\
& & \\
$358-1$ & 1110.25 & 1109.65 \\
& 1110.37 & 1109.75 \\
$358-2$ & 1110.37 & 1109.75 \\
& 1111.29 & 1110.67 \\
$358-3$ & 1111.29 & 1110.67 \\
\hline $358-4$ & 1112.29 & 1111.67 \\
\hline
\end{tabular}

\begin{tabular}{ccc}
\hline \multirow{2}{*}{ Run-Sec. } & \multicolumn{2}{c}{ Depth (m) } \\
& Recorded & Corrected \\
\hline $377-1$ & 1149.30 & 1149.30 \\
& 1149.60 & 1149.60 \\
$377-2$ & 1149.60 & 1149.60 \\
& 1150.60 & 1150.60 \\
$377-3$ & 1150.60 & 1150.60 \\
& 1151.32 & 1151.30 \\
& & \\
$378-1$ & 1151.30 & 1151.30 \\
\hline $378-2$ & 1152.26 & 1152.20 \\
& 1152.26 & 1152.20 \\
\hline $379-1$ & 1153.04 & 1152.98 \\
& 1154.27 & 1152.98 \\
$379-2$ & 1154.27 & 1153.92 \\
& 1155.26 & 1154.90 \\
$379-3$ & 1155.26 & 1154.90 \\
& 1155.66 & 1155.25 \\
& & \\
\hline $380-1$ & 1155.30 & 1155.25 \\
\hline $380-2$ & 1155.88 & 1155.78 \\
\hline $380-3$ & 1155.88 & 1155.78 \\
\hline & 1156.87 & 1156.76 \\
\hline & 1157.40 & 1156.76 \\
\hline
\end{tabular}

\begin{tabular}{|c|c|c|}
\hline \multirow{2}{*}{ Run-Sec. } & \multicolumn{2}{|c|}{ Depth (m) } \\
\hline & \multirow{2}{*}{$\frac{\text { Recorded }}{1217.50}$} & Corrected \\
\hline \multirow{2}{*}{$424-1$} & & 1217.50 \\
\hline & 1218.12 & 1218.09 \\
\hline \multirow{2}{*}{$424-2$} & 1218.12 & 1218.09 \\
\hline & 1219.07 & 1218.96 \\
\hline \multirow{2}{*}{$425-1$} & 1219.00 & 1218.96 \\
\hline & 1219.72 & 1219.66 \\
\hline \multirow{2}{*}{$425-2$} & 1219.72 & 1219.66 \\
\hline & 1220.58 & 1220.50 \\
\hline \multirow{2}{*}{$426-1$} & 1220.50 & 1220.50 \\
\hline & 1221.28 & 1221.28 \\
\hline \multirow{2}{*}{$426-2$} & 1221.28 & 1221.28 \\
\hline & 1221.93 & 1221.93 \\
\hline \multirow{2}{*}{$427-1$} & 1222.00 & 1221.93 \\
\hline & 1222.30 & 1222.23 \\
\hline \multirow{2}{*}{$427-2$} & \multirow{2}{*}{$\begin{array}{l}1222.30 \\
1223.08\end{array}$} & 1222.23 \\
\hline & & 1223.00 \\
\hline & \multicolumn{2}{|c|}{ top depth } \\
\hline & \multicolumn{2}{|c|}{ bottom depth } \\
\hline
\end{tabular}

